\title{
The impact of low- versus standard-volume bowel preparation on participation in primary screening colonoscopy: a randomized health services study
}

(๑) $\odot \ominus$

\author{
Authors \\ Małgorzata Pisera1-3, Robert Franczyk², Paulina Wieszczy ${ }^{1,3}$, Marcin Polkowski, ${ }^{1,2}$, Maciej Rupinski ${ }^{1,2}$, \\ Anna Chaber-Ciopinska ${ }^{1,2}$, Bronislaw Kotowski²,4, Zbigniew Kula ${ }^{5}$, Slawomir Kielek ${ }^{6}$, Marek Buszkiewicz ${ }^{7}$, \\ Maria Rupinska1,2, Jaroslaw Kobiela ${ }^{8}$, Michal Filip Kaminski1-3,9, Jaroslaw Regula1,2
}

Institutions

1 Department of Gastroenterology, Hepatology and Oncology, Center of Postgraduate Medical Education, Warsaw, Poland

2 Department of Gastroenterological Oncology, The M. Sklodowska-Curie Memorial Cancer Center and Institute of Oncology, Warsaw, Poland

3 Department of Cancer Prevention, The M. SklodowskaCurie Memorial Cancer Center and Institute of Oncology, Warsaw, Poland

4 Polish Foundation of Gastroenterology, Warsaw, Poland

5 Department of Endoscopy, The F. Lukaszczyk Oncology Center, Bydgoszcz, Poland

6 Diagnostic and Therapeutic Center "Medyk," Konin and Kalisz, Poland

7 NZOZ ENDOMED, Gorzow Wielkopolski, Poland

8 Department of General, Endocrine and Transplant Surgery, Medical University of Gdansk, Gdansk, Poland

9 Department of Health Management and Health Economics, University of Oslo, Oslo, Norway

submitted 25.4.2018

accepted after revision 31.8 .2018

Bibliography

DOI https://doi.org/10.1055/a-0748-5479

Published online: 11.1.2019 | Endoscopy 2019; 51: 227-236

(c) Georg Thieme Verlag KG Stuttgart · New York

ISSN 0013-726X

Corresponding author

Małgorzata Pisera, MD, Department of Cancer Prevention, The M. Sklodowska-Curie Memorial Cancer Center and Institute of Oncology, W.K. Roentgena 5 Str., Warsaw 02-781, Poland

Fax: +48-22-5463021

mpisera@gmail.com

Table e5

Online content viewable at:

https://doi.org/10.1055/a-0748-5479

\section{ABSTRACT}

Background The aim of this study was to evaluate the impact of low-volume vs. standard-volume bowel preparation on participation in screening colonoscopy, bowel preparation quality, and lesion detection rates.

Methods This was a multicenter, randomized, health services study within the population-based primary colonoscopy screening program in Poland. Individuals aged $55-62$ years were randomized in a 1:1 ratio to bowel preparation with a low-volume $(0.3 \mathrm{~L}$ sodium picosulfate with magnesium citrate) or standard-volume ( $4 \mathrm{~L}$ polyethylene glycol) regimen and then invited to participate in screening colonoscopy. The primary outcome measure was the rate of participation in screening colonoscopy. Compliance with the assigned bowel preparation, bowel preparation quality, and lesion detection rates were also evaluated.

Results A total of 13621 individuals were randomized and 13497 were analyzed (6752 in the low-volume group and 6745 in the standard-volume group). The participation rate (16.6\% vs. $15.5 \% ; P=0.08$ ) and compliance rate ( $93.3 \%$ vs. $94.1 \% ; P=0.39)$ did not differ significantly between the groups. In the low-volume group, fewer participants had adequate bowel preparation compared with the standardvolume group (whole colon $79.0 \%$ vs. $86.4 \%, P<0.001$; proximal colon $80.1 \%$ vs. $87.3 \%, P<0.001)$. Detection rates of advanced adenoma (AADR) and advanced serrated polyps (ASPDR) were lower in the low-volume group than in the standard-volume group (AADR in the proximal colon $2.6 \%$ vs. $4.3 \%, P=0.02$; ASPDR in the whole colon $2.0 \%$ vs. $3.3 \%, P=0.04$; ASPDR in the proximal colon $1.0 \%$ vs. $1.9 \%$, $P=0.048)$.

Conclusion When compared with a standard-volume bowel preparation with polyethylene glycol, low-volume bowel preparation with sodium picosulfate/magnesium citrate did not improve participation rate or lesion detection rates, and negatively affected bowel preparation quality.

TRIAL REGISTRATION: multicenter, paralel group, health service randomized study RHS 005_2014_january at Finnish Cancer Registry 


\section{Introduction}

Colorectal cancer (CRC) is the second leading cause of cancerrelated death in Europe and the USA [1,2]. Screening colonoscopy has been shown to decrease CRC incidence and mortality [3]; however, its effectiveness depends on many factors, including colonoscopy quality and participation of the target population [4]. Satisfactory participation rates of $60 \%-75 \%$ have been reached in Scandinavian countries and the USA [57], but in most European countries rates remain much lower, ranging from $10 \%$ to $34 \%$ [7-12]. Bowel preparation, especially the large volume of the cleansing agent solution that needs to be ingested, is frequently indicated as one of the major reasons for nonparticipation in screening colonoscopy [13-15]. A low-volume preparation was shown to have similar effectiveness to standard 4-L regimens but was better tolerated by patients and was associated with higher patient satisfaction and increased willingness to repeat identical preparation in the future $[16,17]$. Moreover, a low-volume preparation given in a split-dose regimen provided superior bowel cleansing and had a good safety profile compared with 4-L polyethylene glycol (PEG) administered the day before colonoscopy [18].

We hypothesized, therefore, that a low-volume regimen may increase participation in primary screening colonoscopy without compromising the quality of bowel preparation. The primary aim of this randomized health services study was to evaluate whether low-volume bowel preparation improves the participation in primary screening colonoscopy compared with the standard-volume preparation of $4 \mathrm{~L}$ PEG. Secondary aims were to compare compliance with the assigned bowel preparation, the quality of bowel preparation, and lesion detection rates in screening participants.

\section{Methods}

\section{Study design and settings}

This multicenter, parallel-group, randomized, health services study was conducted between March and December 2015, within the Polish Colonoscopy Screening Program (PCSP), an organized, population-based, primary colonoscopy screening program described elsewhere $[19,20]$. The study was coordinated by the PCSP Main Office and involved six screening centers - two academic and four private - which were selected based on screening colonoscopy volume, quality indicators, and geographic location to include both urban and rural areas.

\section{Participants and intervention}

Study participants were randomly drawn from individuals eligible for PCSP in 2015, including men and women aged 55-62 years who were registered in the Polish Population Registry and living in the areas served by the six participating screening centers. The Polish National Cancer Registry and PCSP databases were searched to identify and exclude individuals with a previous CRC diagnosis and/or who had previously undergone screening colonoscopy. The remaining individuals were randomly assigned in a 1:1 ratio to bowel preparation for colonoscopy with a low-volume regimen $(0.3 \mathrm{~L}$ of oral sodium picosul- fate with magnesium citrate solution) or a standard-volume regimen (4L of PEG solution). Randomized individuals were mailed a personalized letter inviting them to participate, freeof-charge, in colonoscopy screening with a proposed colonoscopy date in 6 weeks' time. The letter outlined the purpose of screening and advised the invitees to contact the local screening center in order to receive more information and schedule their pre-colonoscopy visit. If no response was received within 3 weeks, a reminder letter was sent.

During the pre-colonoscopy visit, screening center personnel conducted the following activities: 1 ) reviewed the medical history of each individual to ensure that no contraindications to bowel preparation and/or screening colonoscopy were present; 2) provided detailed information about screening colonoscopy and the assigned bowel preparation; 3) dispensed the assigned preparation agent with written instructions on how to prepare for colonoscopy. Participants were not informed that they were participating in a study.

\section{Study procedures}

Bowel preparation for colonoscopy

Bowel preparation was in accordance with the European Society of Gastrointestinal Endoscopy recommendations [21]. On the day before colonoscopy, a low-residue breakfast and lunch (blended soup or broth) up to 15:00, followed by clear liquids in the afternoon, were recommended. On the day of colonoscopy, only clear liquids were allowed. Dietary restrictions were the same in both groups and did not differ depending on whether a split or nonsplit regimen was used. Preparation agents were used in standard doses in all individuals, irrespectively of their body mass. Day-before preparation was recommended for individuals who were scheduled for sedated morning colonoscopy in line with anesthesiologists' recommendations; a split-dose regimen was recommended for unsedated colonoscopy. The cleansing solution was prepared according to the manufacturer's instructions provided in the patient information leaflet and was self-administered by the patients.

Individuals in the low-volume group were prepared with oral sodium picosulfate/magnesium citrate solution (CitraFleet; Laboratories Casen-Fleet, Zaragoza, Spain) administered as an evening/morning split dose $(2 \times 0.15 \mathrm{~L})$ or the day before colonoscopy $(0.3 \mathrm{~L})$. They were strongly advised to ingest an additional $4 \mathrm{~L}$ of water or clear liquids during preparation. Preparation in the standard-volume group consisted of oral PEG solution (Fortrans; IpsenPharma, Boulogne Billancourt, France) administered as an evening/morning split-dose $(2 \times 2 \mathrm{~L})$ or the day before colonoscopy $(4 \mathrm{~L})$.

\section{Screening colonoscopy}

Colonoscopies were performed on an outpatient basis. Before colonoscopy, participants completed a simple questionnaire with questions on bowel preparation, the name of the agent used to cleanse the bowel, administration regimen, and whether or not the whole prescribed amount of cleansing solution and additional fluids were ingested. Sedation was not used routinely. Individuals with a history of abdominal/pelvic surgery 
and/or unwillingness to undergo unsedated colonoscopy were offered sedation according to local center policy [22].

Standard or high resolution video colonoscopes were used. Polyps $\leq 10 \mathrm{~mm}$ diameter were removed immediately; polyps $>10 \mathrm{~mm}$ were removed either immediately or during a separate procedure on an inpatient basis. Other abnormalities were biopsied. All lesions removed or biopsied (including polyps $>10 \mathrm{~mm}$ removed during the separate inpatient procedure) were assessed histologically and included in the analysis. Categorization was performed according to the most advanced lesion [23].

\section{Outcome measures}

The primary outcome was the screening colonoscopy participation rate, defined as the proportion of individuals invited for screening who had colonoscopy performed within 90 days from the date proposed in the invitation letter.

Secondary outcomes included self-reported compliance, quality of bowel preparation, and lesion detection rates. Selfreported compliance with the assigned bowel preparation was defined as ingestion of the full dose of the assigned preparation agent, together with the recommended amount of water (clear liquids), as assessed by the questionnaire completed before screening colonoscopy. The quality of bowel preparation was assessed using the Boston Bowel Preparation Scale (BBPS) in the whole and proximal colon (cecum, ascending colon, and transverse colon including the splenic flexure). Adequate preparation was defined as BBPS score of $\geq 2$ in each colon segment [24]. All participating endoscopists received training in BBPS use.

Lesion detection rates for the whole and proximal colon were defined as the proportion of individuals with at least one lesion of a given type detected on colonoscopy: 1) polyp detection rate (PDR; any polyp); 2) adenoma detection rate (ADR; any adenoma, traditional serrated adenoma or adenocarcinoma); 3) advanced adenoma detection rate (AADR; adenoma with any of the following characteristics: $\geq 10 \mathrm{~mm}$, villous component, high grade dysplasia, adenocarcinoma, or traditional serrated adenoma $\geq 10 \mathrm{~mm}$ ); 4) advanced serrated polyp detection rate (ASPDR; hyperplastic polyp $\geq 10 \mathrm{~mm}$, sessile serrated polyp/adenoma, traditional serrated adenoma) [25].

\section{Randomization and blinding}

Randomization was performed by the study statistician and was stratified by study center, and by participant age and sex. Endoscopists and endoscopy nurses were blinded to participant allocation and the type of bowel preparation administered. They were instructed not to ask the participants about bowel preparation details.

\section{Sample size and statistical methods}

The expected participation rates in the standard-volume and low-volume groups were $21 \%$ and $23 \%$, respectively, based on the current participation rate in the PCSP (unpublished data). In order to detect this 2 percentage point difference between two independent rates with $80 \%$ power at a $5 \%$ level of significance,
13468 participants needed to be randomized in a 1:1 ratio and invited for screening colonoscopy.

The primary outcome was assessed by intention-to-treat analysis in all randomized individuals after excluding those who died or were diagnosed with CRC before the date of randomization, and those to whom the invitation letter could not be delivered (return of an unopened letter with post office annotation "addressee unknown").

Secondary outcomes were assessed in all individuals who had colonoscopy performed up to the end of 2015, including both those who did and did not reach the primary outcome.

Categorical variables were compared using chi-squared test or Fisher exact test. Univariable and multivariable logistic regression analyses were performed to identify factors that influenced participation rate in the study. Forward stepwise regression at a 0.1 significance level was used for variable selection. Study center, participant age, sex, and travel distance to the study center, and average per capita income in the area of residence were tested for inclusion in the multivariable model. Odds ratios (ORs) and $95 \%$ confidence intervals (Cls) were reported. All tests were two sided. A P value of $<0.05$ was considered to denote a statistically significant difference.

All analyses were performed using Stata software, version 13.1 (Stata Corp., College Station, Texas, USA). Figures were prepared using R statistical software, version 3.0.1 (R Development Core Team, Vienna, Austria).

\section{Ethical issues}

The research proposal was reviewed by the institutional review board at the authors' institutions and was judged to be exempt from oversight (5 March 2014). Participants signed an informed consent for screening colonoscopy within the PCSP in the routine way. Because this was a randomized health services study, no separate informed consent to participate in the study was obtained [19]. The study was registered at the Finnish Cancer Registry (No.RHS 005_2014_january).

\section{Results}

A total of 13621 individuals aged $55-62$ years were randomly assigned to the low-volume $(n=6811)$ or standard-volume $(n=$ 6810) groups and invited to screening colonoscopy. After exclusion of 124 individuals who had died $(n=68)$ or were diagnosed with CRC before the randomization date $(n=3)$, or the invitation letter could not be delivered to them $(n=53)$, a total of 13497 individuals (6752 and 6745 in the low-volume and standard-volume groups, respectively), were included in the intention-to-treat analysis ( $\mathbf{F i g} \mathbf{1}$ ). Baseline characteristics of the study groups are shown in $>$ Table 1 .

\section{Participation rate}

A total of 1119 (16.6\%) and 1044 (15.5\%) individuals in the low-volume and standard-volume groups, respectively $(P=$ 0.08 ), underwent screening colonoscopy within 90 days from the date proposed in the invitation letter and reached the primary outcome. Reasons for nonparticipation in screening are summarized in $>$ Table 2. 
Individuals eligible for participation in PCSP in 2015*

\section{$\checkmark$}

13621 men and women, 55 - 62 years, randomized and invited to participate in screening colonoscopy

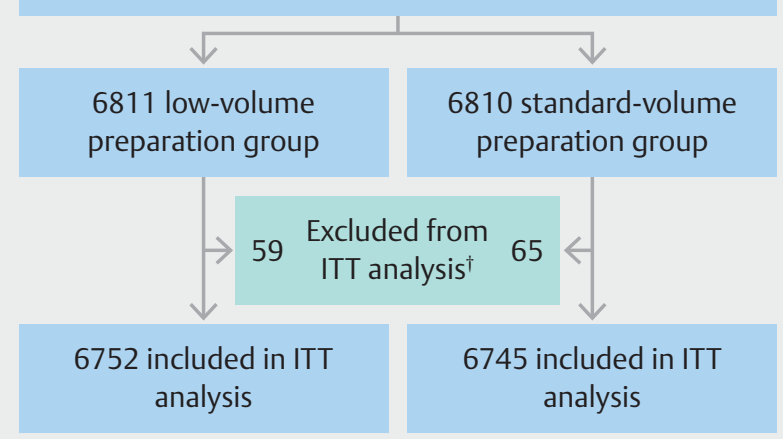

- Fig. 1 Participant flow chart. ITT, intention-to-treat; PCSP, Polish Colonoscopy Screening Program. * Men and women aged 55-64 years registered in the Polish Population Registry. ${ }^{\dagger} 124$ individuals who had been randomized and invited to screening colonoscopy were excluded: 68 had died and 3 had been diagnosed with colorectal cancer before the randomization date, and the invitation letter could not be delivered to 53 individuals.

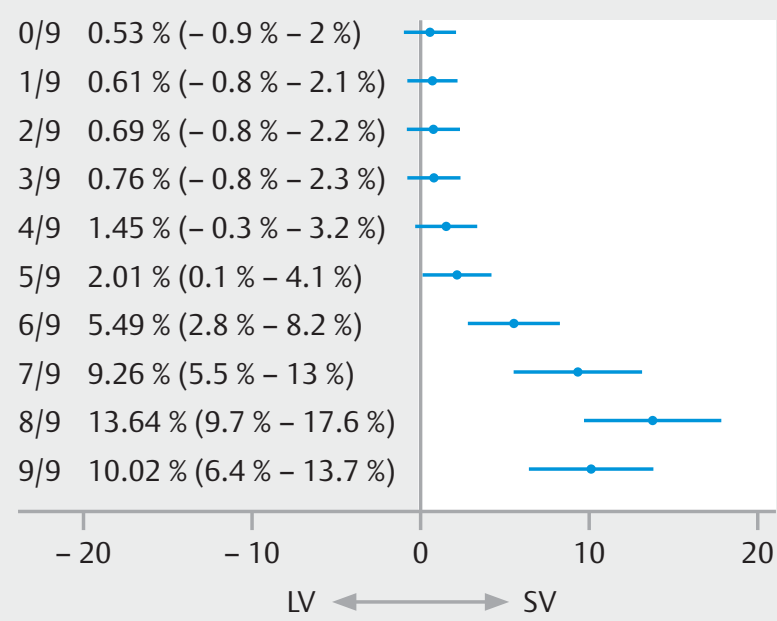

- Fig. 2 Forest plot of cumulative percentage (with 95\% confidence intervals) differences between groups in bowel preparation

The multivariate analysis model ( $\triangleright$ Table 3 ) showed that factors significantly affecting participation rate were participant sex (men vs. women OR 1.15, 95\% Cl 1.05-1.26; $P<0.004$ ), screening center (E vs. A OR 1.39, $95 \% \mathrm{Cl} 1.20-1.62, P<0.001$; D vs. A OR 1.35, $95 \% \mathrm{Cl} 1.13-1.62, P=0.001$; and $C$ vs. A OR $1.23,95 \% \mathrm{Cl} 1.01-1.50, P=0.04)$, and travel distance to the screening center $(\geq 45 \mathrm{~km}$ vs. $<10 \mathrm{~km}$ OR $0.52,95 \% \mathrm{Cl} 0.44-$ $0.63, P<0.001 ; 25-44 \mathrm{~km}$ vs. $<10 \mathrm{~km}$ OR $0.84,95 \% \mathrm{Cl} 0.72-$ $0.98, P=0.02$ ). Allocation to the low-volume or standard-vol- ume group did not have a significant impact on the participation rate.

\section{Secondary outcomes}

Secondary outcomes ( $\triangleright$ Table 4 ) were assessed in 2456 individuals (1249 in the low-volume group and 1207 in the standardvolume group). This group included 2163 individuals who reached the primary outcome and 293 individuals who had colonoscopy performed later than 90 days from the date proposed in invitation letter (up to the end of 2015). Data on the use of split and nonsplit regimens and sedation for colonoscopy are presented in $>$ Supplementary Table 5 (available online).

\section{Compliance}

The assigned bowel preparation agent was used by 1183 (94.7\%) and 1174 (97.3\%) participants in the low-volume and standard-volume groups, respectively $(P=0.001)$. A total of 1231 (98.6\%) and 1168 (96.8\%) participants, respectively, reported ingestion of the full recommended dose of liquids ( $P=$ $0.003)$. The proportion of individuals who met both conditions (1165 [93.3\%] and 1136 [94.1\%], respectively), did not differ significantly between groups $(P=0.39)$.

\section{Bowel preparation quality}

Adequate bowel preparation of the whole colon was achieved in 987 (79.0\%) and 1043 (86.4\%) participants in the low-volume and standard-volume groups, respectively $(P<0.001)$. Adequate preparation of the proximal colon was achieved in 1001 $(80.1 \%)$ and 1054 (87.3) participants, respectively $(P<0.001)$. The differences in favor of the standard-volume group became more pronounced when the more stringent criteria for preparation quality were applied ( $\bullet$ Fig. 2).

\section{Lesion detection rates}

In the whole colon PDR, ADR, and AADR did not differ significantly between groups; ASPDR was significantly lower in the low-volume vs. standard-volume group $(2.0 \%$ vs. $3.3 \%$; $P=$ $0.04)$. In the proximal colon PDRs and ADRs did not differ significantly between groups; $\operatorname{AADR}(2.6 \%$ vs. $4.3 \% ; P=0.02)$ and ASPDR ( $1.0 \%$ vs. $1.9 \% ; P=0.048)$ were significantly lower in the low-volume vs. standard-volume groups. When only individuals with adequate bowel preparation were considered, lesion detection rates did not differ significantly between groups except for ASPDR, which was lower in the low-volume vs. standard-volume group (whole colon $1.7 \%$ vs. $3.6 \%, P=0.01$; proximal colon $0.5 \%$ vs. $2.0 \%, P=0.003)$.

\section{Discussion}

This is the first population-based, randomized study to investigate whether low-volume sodium picosulfate/magnesium citrate bowel preparation can improve participation in screening colonoscopy when compared with standard-volume PEG preparation. The answer to this research question is negative. Not only did the use of the low-volume preparation fail to improve the participation rate in screening colonoscopy, but it also failed to offer advantages in terms of better compliance, bowel 
- Table 1 Baseline characteristics of study groups.

\begin{tabular}{|c|c|c|c|}
\hline Groups & Low-volume group & Standard-volume group & $P$ value \\
\hline Total, n & 6752 & 6745 & \\
\hline Sex, n (\%) & & & 0.98 \\
\hline - Men & $3179(47.1)$ & $3174(47.1)$ & \\
\hline - Women & $3573(52.9)$ & $3571(52.9)$ & \\
\hline Age, n (\%) & & & 0.06 \\
\hline - 55-59 years & $5088(75.4)$ & $4986(73.9)$ & \\
\hline - $60-62$ years & $1664(24.6)$ & $1759(26.1)$ & \\
\hline Screening center, n (\%) & & & 0.50 \\
\hline - A & $1164(17.2)$ & $1171(17.4)$ & \\
\hline . B & $1778(26.3)$ & $1716(25.4)$ & \\
\hline . C & $609(9.0)$ & $604(9.0)$ & \\
\hline . D & $762(11.3)$ & $725(10.7)$ & \\
\hline - E & $1552(23.0)$ & $1637(24.3)$ & \\
\hline . $F$ & $887(13.1)$ & $892(13.2)$ & \\
\hline Area of residence, n (\%) & & & 0.22 \\
\hline - Urban & $4073(60.3)$ & $3999(59.3)$ & \\
\hline " Rural & $2679(39.7)$ & $2746(40.7)$ & \\
\hline Travel distance to the screening center, $\mathrm{n}(\%)$ & & & 0.45 \\
\hline . $<45 \mathrm{~km}$ & $4933(73.1)$ & $4889(72.5)$ & \\
\hline . $\geq 45 \mathrm{~km}$ & $1819(26.9)$ & $1856(27.5)$ & \\
\hline Average income in the area of residence, $n(\%)$ & & & 0.25 \\
\hline - scountry-wide average & $4790(70.9)$ & $4724(70.1)$ & \\
\hline - >country-wide average & $1962(29.1)$ & $2021(29.9)$ & \\
\hline
\end{tabular}

- Table 2 Reasons for nonparticipation in screening colonoscopy.

\begin{tabular}{|c|c|c|c|}
\hline & $\begin{array}{l}\text { Low-volume } \\
\text { group }\end{array}$ & $\begin{array}{l}\text { Standard-volume } \\
\text { group }\end{array}$ & Total \\
\hline Individuals in the ITT analysis, $\mathrm{n}$ & 6752 & 6745 & 13497 \\
\hline Did not respond to invitation/reminder letter, n (\%) & $4533(67.1)$ & $4616(68.4)$ & $9149(67.8)$ \\
\hline Responded to invitation but did not undergo screening colonoscopy, n (\%) & $970(14.4)$ & $922(13.7)$ & $1892(14.0)$ \\
\hline Colonoscopy within 2 years before invitation & $171(2.5)$ & $137(2.0)$ & $308(2.3)$ \\
\hline Contraindications to bowel preparation or screening colonoscopy & $21(0.3)$ & $10(0.1)$ & $31(0.2)$ \\
\hline Moved out of the area served by participating screening centers & $65(1.0)$ & $54(0.8)$ & $119(0.9)$ \\
\hline Did not consent to participate in screening & $691(10.2)$ & $699(10.4)$ & $1390(10.3)$ \\
\hline Withdraw consent after receiving bowel preparation instructions & $22(0.3)$ & $22(0.3)$ & $44(0.3)$ \\
\hline Responded to invitation and underwent screening colonoscopy, n (\%) & $1249(18.5)$ & $1207(17.9)$ & $2456(18.2)$ \\
\hline Colonoscopy $\leq 90$ days from the date proposed in the invitation letter & $1119(16.6)$ & $1044(15.5)$ & $2163(16.0)$ \\
\hline Colonoscopy $>90$ days from the date proposed in the invitation letter & $130(1.9)$ & $163(2.4)$ & $293(2.2)$ \\
\hline
\end{tabular}


- Table 3 Odds ratios of participation in screening colonoscopy.

\begin{tabular}{|c|c|c|c|c|c|c|}
\hline \multirow[t]{2}{*}{ Variables } & \multicolumn{3}{|c|}{ Univariable analyses } & \multicolumn{3}{|c|}{ Multivariable analyses* } \\
\hline & OR & $95 \% \mathrm{Cl}$ & $P>z$ & OR & $95 \% \mathrm{Cl}$ & $P>z$ \\
\hline \multicolumn{7}{|l|}{ Study group } \\
\hline - Standard volume & Reference & & & Reference & & \\
\hline - Low volume & 1.08 & $0.99-1.19$ & 0.08 & 1.09 & $0.99-1.19$ & 0.08 \\
\hline \multicolumn{7}{|l|}{ Sex } \\
\hline - Women & Reference & & & Reference & & \\
\hline - Men & 1.12 & $1.03-1.23$ & 0.01 & 1.15 & $1.05-1.26$ & 0.004 \\
\hline \multicolumn{7}{|l|}{ Age } \\
\hline . $55-59$ years & Reference & & & & & \\
\hline . $60-62$ years & 1.32 & $1.19-1.46$ & $<0.001$ & & & \\
\hline \multicolumn{7}{|l|}{ Area of residence } \\
\hline - Rural & Reference & & & & & \\
\hline - Urban & 0.98 & $0.89-1.07$ & 0.62 & & & \\
\hline \multicolumn{7}{|c|}{ Travel distance to the screening centre } \\
\hline . $<10 \mathrm{~km}$ & Reference & & & Reference & & \\
\hline . $10-24 \mathrm{~km}$ & 0.90 & $0.79-1.03$ & 0.11 & 0.95 & $0.81-1.09$ & 0.45 \\
\hline - $25-44 \mathrm{~km}$ & 0.86 & $0.74-0.99$ & 0.03 & 0.84 & $0.72-0.98$ & 0.02 \\
\hline . $\geq 45 \mathrm{~km}$ & 0.48 & $0.41-0.56$ & $<0.001$ & 0.52 & $0.44-0.63$ & $<0.001$ \\
\hline \multicolumn{7}{|c|}{ Average income in the area of residence } \\
\hline - <country-wide average & Reference & & & & & \\
\hline . $\geq$ country-wide average & 1.29 & $1.17-1.42$ & $<0.001$ & & & \\
\hline \multicolumn{7}{|l|}{ Screening center } \\
\hline - A & Reference & & & & & \\
\hline . B & 0.77 & $0.66-090$ & 0.001 & 1.01 & $0.85-1.19$ & 0.92 \\
\hline$\cdot C$ & 1.24 & $1.03-1.49$ & 0.03 & 1.23 & $1.01-1.50$ & 0.04 \\
\hline . D & 1.40 & $1.18-1.66$ & $<0.001$ & 1.35 & $1.13-1.62$ & 0.001 \\
\hline . E & 1.37 & $1.18-1.58$ & $<0.001$ & 1.39 & $1.20-1.62$ & $<0.001$ \\
\hline . $F$ & 1.17 & $1.00-1.39$ & 0.06 & 1.04 & $0.87-1.25$ & 0.67 \\
\hline
\end{tabular}

preparation quality, and lesion detection rates. In fact, in this largest study to date, bowel preparation quality and some of the evaluated lesion detection rates (ASPDR) were significantly lower in participants prepared with the low-volume sodium picosulfate/magnesium citrate regimen ( $\mathbf{F i g . 3}$ ). We believe, therefore, that sodium picosulfate/magnesium citrate-based low-volume bowel preparation should not be recommended for screening colonoscopy.

The total volume of fluid recommended to be ingested for preparation was nearly the same in both groups $(4.3 \mathrm{~L}$ and $4.0 \mathrm{~L}$ in the low-volume and standard-volume groups, respectively); however, the amount of distasteful cleansing agent so- lution in the low-volume group was only $0.3 \mathrm{~L}$, which is much lower than the $4.0 \mathrm{~L}$ of PEG solution required in the standardvolume regimen. Although we originally assumed that this difference might significantly affect participation in screening colonoscopy, our results showed the opposite. In fact, the vast majority of those who did not participate, either did not respond to the invitation at all or refused to participate before the preparation instructions were given to them. Therefore, in most cases, the knowledge of differences between low- and standard-volume preparations and their potential advantages or disadvantages could not affect individuals' decisions to participate in screening. The number of individuals who withdrew 
- Table4 Secondary outcomes.

\begin{tabular}{|c|c|c|c|c|}
\hline Groups & Low volume group & $\begin{array}{l}\text { Standard volume } \\
\text { group }\end{array}$ & $P$ value & Total \\
\hline Total, n & 1249 & 1207 & & 2456 \\
\hline \multicolumn{5}{|l|}{ Compliance, $n(\%)$} \\
\hline - Preparation agent as allocated & $1183(94.7)$ & $1174(97.3)$ & 0.001 & $2357(96.0)$ \\
\hline - Consumed the total amount of liquid ${ }^{1}$ & $1231(98.6)$ & $1168(96.8)$ & 0.003 & $2399(97.7)$ \\
\hline - Both & $1165(93.3)$ & $1136(94.1)$ & 0.39 & $2301(93.7)$ \\
\hline \multicolumn{5}{|l|}{ Quality of bowel preparation ${ }^{2}, \mathrm{n}(\%)$} \\
\hline - BBPS $\geq 2 / 2 / 2$ & $987(79.0)$ & $1043(86.4)$ & $<0.001$ & $2030(82.7)$ \\
\hline \multicolumn{5}{|l|}{ - BBPS cumulative values } \\
\hline - $\geq 6 / 9$ & $1047(83.8)$ & $1078(89.3)$ & $<0.001$ & $2125(86.5)$ \\
\hline . $\geq 7 / 9$ & $767(61.4)$ & $853(70.7)$ & $<0.001$ & $1620(66.0)$ \\
\hline . $\geq 8 / 9$ & $553(44.3)$ & $699(57.9)$ & $<0.001$ & $1252(51.0)$ \\
\hline . 9/9 & $326(26.1)$ & $436(36.1)$ & $<0.001$ & $762(31.0)$ \\
\hline - $\mathrm{BBPS} \geq 2$ in the right colon & $1019(81.6)$ & $1065(88.2)$ & $<0.001$ & $2084(84.9)$ \\
\hline - $\mathrm{BBPS} \geq 2 / 2$ in the proximal colon & $1001(80.1)$ & $1054(87.3)$ & $<0.001$ & $2055(83.7)$ \\
\hline \multicolumn{5}{|l|}{ Lesion detection rates overall, n (\%) } \\
\hline \multicolumn{5}{|l|}{ Whole colon } \\
\hline - PDR & $535(42.8)$ & $512(42.4)$ & 0.82 & $1047(42.6)$ \\
\hline - $A D R$ & $377(30.2)$ & $355(29.4)$ & 0.67 & $732(29.8)$ \\
\hline - AADR & $97(7.8)$ & $104(8.6)$ & 0.45 & $201(8.2)$ \\
\hline - ASPDR & $25(2.0)$ & $40(3.3)$ & 0.04 & $65(2.6)$ \\
\hline - Missing data & $2(<0.1)$ & $1(<0.1)$ & & $3(<0.1)$ \\
\hline \multicolumn{5}{|l|}{ Proximal colon } \\
\hline - PDR & $256(20.5)$ & $258(21.4)$ & 0.59 & $514(20.9)$ \\
\hline - $A D R$ & $194(15.5)$ & $195(16.2)$ & 0.67 & $389(15.8)$ \\
\hline - AADR & $33(2.6)$ & $52(4.3)$ & 0.02 & $85(3.5)$ \\
\hline - ASPDR & $12(1.0)$ & $23(1.9)$ & 0.048 & $35(1.4)$ \\
\hline - Missing data & & $1(<0.1)$ & & $1(<0.1)$ \\
\hline \multicolumn{5}{|c|}{ Lesion detection rates in participants with BBPS $\geq 2 / 2 / 2, n(\%)$} \\
\hline - Whole colon & $\mathrm{n}=987$ & $\mathrm{n}=1043$ & & \\
\hline - PDR & $425(43.1)$ & $460(44.1)$ & 0.64 & $885(43.6)$ \\
\hline - $A D R$ & $308(31.2)$ & $316(30.3)$ & 0.66 & $624(30.8)$ \\
\hline - AADR & $82(8.3)$ & $81(7.8)$ & 0.65 & $163(8.0)$ \\
\hline - ASPDR & $17(1.7)$ & $37(3.6)$ & 0.01 & $54(2.7)$ \\
\hline - Missing data & $1(<0.1)$ & $1(<0.1)$ & & $2(<0.1)$ \\
\hline - Proximal colon & $\mathrm{n}=987$ & $\mathrm{n}=1043$ & & \\
\hline - PDR & $203(20.6)$ & $238(22.8)$ & 0.22 & $441(21.8)$ \\
\hline - ADR & $158(16.0)$ & $177(17.0)$ & 0.56 & $335(16.5)$ \\
\hline
\end{tabular}


- Table4 (Continuation)

\begin{tabular}{|l|l|l|l|l|}
\hline Groups & Low volume group & $\begin{array}{l}\text { Standard volume } \\
\text { group }\end{array}$ & P value & Total \\
\hline - AADR & $27(2.7)$ & $43(4.1)$ & 0.09 & $70(3.5)$ \\
\hline - ASPDR & $5(0.5)$ & $21(2.0)$ & 0.003 & $26(1.3)$ \\
\hline - Missing data & & $1(<0.1)$ & $1(<0.1)$ \\
\hline $\begin{array}{l}\text { BBPS, Boston Bowel Preparation Scale; PDR, polyp detection rate; ADR, adenoma detection rate; AADR, advanced adenoma detection rate; ASPDR, advanced serra- } \\
\text { ted polyp detection rate. }\end{array}$ \\
$\begin{array}{l}1 \text { Low-volume group: } 0.3 \mathrm{~L} \text { of cleansing agent solution + } 4 \text { L of additional water/clear liquids; standard-volume group: 4L polyethylene glycol solution. } \\
\text { 2 Data for the three colon sections. }\end{array}$
\end{tabular}

their consent to screening after receiving bowel preparation instructions was negligibly low in both groups ( $0.3 \%)$. This corroborates previous data indicating that the fear of preparation and colonoscopy in general, rather than details such as the volume and type of cleansing solution, is the most significant barrier to participation in CRC screening [13-15].

Men, people aged 60-62 years, those living closer to the screening center and in more affluent areas were more likely to participate in screening colonoscopy than women, people aged 55-59 years, and those living farther away from the screening center and in less affluent areas. Similar results were reported in previous studies $[7,10,14]$. In the multivariable model in the present study, only sex, travelling distance to the screening center, and the screening center itself were factors significantly associated with participation rate.

The compliance rates were similar in both groups and generally high; however, when the components of this composite outcome measure were analyzed separately, significant differences between the groups were observed. In the low-volume group, participants were less likely to prepare with the allocated regimen but more likely to ingest the whole recommended amount of liquid. The reason for using a preparation other than the one allocated was that some participants obtained the bowel cleansing agent from their general practitioner rather than from the screening center. Because $4 \mathrm{~L}$ PEG is by far the most popular cleansing agent in Poland, the general practitioner was more likely to recommend standard-volume rather than low-volume preparation.

An interesting new finding is that although overall compliance rates did not differ between groups, and the individuals in the low-volume group were more likely to ingest the whole recommended amount of fluid, they were less likely to achieve adequate bowel preparation, both for the whole and the proximal colon. Moreover, the differences in preparation quality in favor of standard-volume preparation became more pronounced when more stringent criteria of preparation quality were applied. Compared with the low-volume group, the rates of individuals who achieved BBPS scores of $\geq 6 / 9, \geq 7 / 9, \geq 8 / 9$, and $9 / 9$ in the standard-volume group were higher by 5.5, 9.3, 13.6, and 10.0 percentage points, respectively. Previously, insignificant differences in bowel preparation quality and better tolerance of sodium picosulphate/magnesium citrate solution compared with PEG were reported [26-30]. Previous stud- ies, however, were limited in size and demonstrated some methodological uncertainties leading to the conclusion that large, well-designed studies are warranted [26].

The low-volume preparation did not offer any advantages over standard-volume preparation in terms of lesion detection rates. In fact, higher detection rates of advanced lesions (ASPDR in the whole and proximal colon, and AADR in the proximal colon) were observed in the standard-volume group. These findings, however, should be treated with caution, because they were not accompanied by higher detection rates of nonadvanced lesions (ADR and PDR).

The present study evaluated a large number of individuals drawn from a homogeneous, average CRC risk population, and was conducted within a well-established screening program as a randomized health services study. The participating screening centers were selected based on quality indicators. The participating endoscopists were trained in BBPS use and blinded to evaluated individuals' allocation.

We acknowledge the following limitations of the present study. Individuals aged 63-64 years, who are normally eligible for PCSP and demonstrate the highest compliance with screening, were not included in the present study because of administrative reasons (within each calendar year, the PSCP invites participants in descending order of age; individuals aged 63-64 years were invited in the first months of the year, before the study start). A total of 124 randomized individuals ( $0.9 \%$ ) were excluded from the ITT analysis because the invitation letter could not be delivered to them or, as it turned out, they had died or had been diagnosed with CRC before the randomization date. The number of individuals excluded for these reasons was similar in both groups. A further 308 individuals who responded to the invitation could not participate in screening because they had already undergone screening colonoscopy within the previous 2 years. Because this examination was done outside the PCSP, it was not recorded in the PCSP database and crosschecked before randomization and the sending of invitation letters.

The primary outcome measure - participation in screening colonoscopy - was arbitrarily defined as colonoscopy performed within 90 days from the date proposed in the invitation letter. This definition was chosen because it considers all possible factors affecting individuals' decisions to participate or not participate in screening that might be involved during the peri- 
Men and women, aged 5562 years $n=13621$

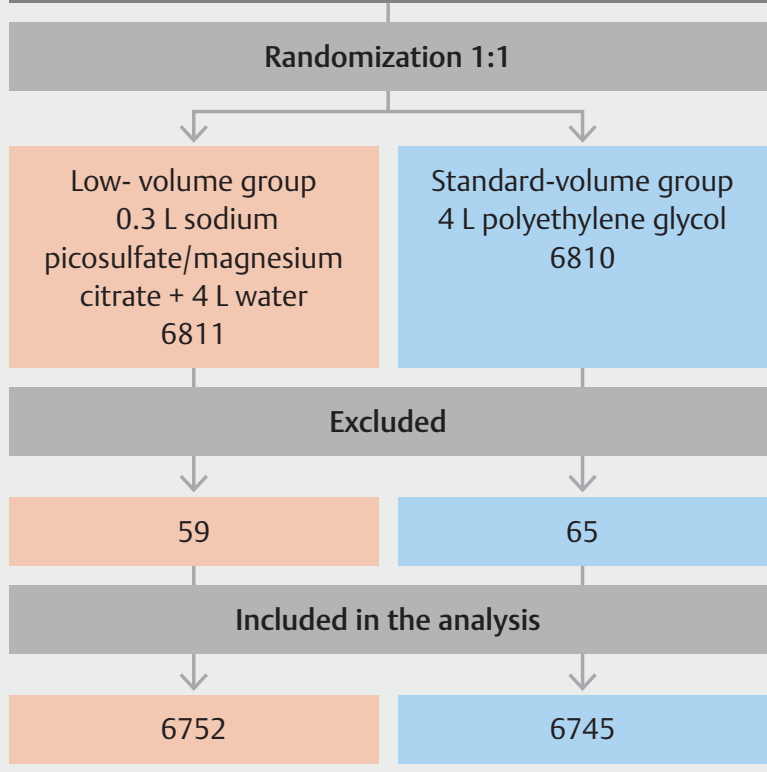

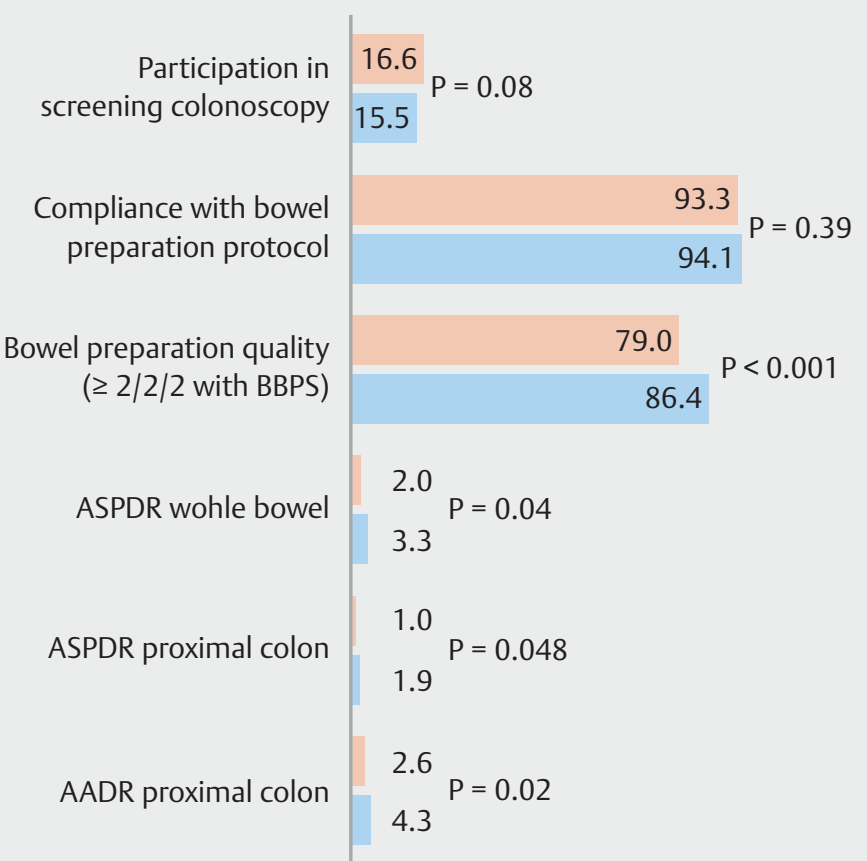

- Fig. 3 Summary of study design and main results. BBPS, Boston Bowel Preparation Scale; AADR, advanced adenoma detection rate; ASPDR, advanced serrated polyp detection rate.

od between the invitation and screening colonoscopy. A sample size of 13468 individuals was large enough to detect a small difference of $2 \%$ in participation rates between groups. Randomization was done before invitation to screening in order to exclude the potential influence of the PCSP personnel, who provided the information about bowel preparation, on individuals' decision to participate or not participate. The proportion of individuals who did not respond to the invitation, did not attend the pre-colonoscopy visit, and hence did not receive any information on the assigned bowel preparation was similar in the two groups. With a time frame longer than 90 days, the participation rate would be higher. In fact, it increased by $2.2 \%$ from $16.0 \%$ to $18.2 \%$ - when all individuals who underwent colonoscopy up to the end of 2015 were analyzed, including both those who did and did not meet the 90-day limit. The increase was similar in both groups.

In $39 \%$ of individuals, bowel preparation was administered as nonsplit, day-before dosing and this might have negatively affected the quality of bowel preparation. The proportion of individuals prepared in this way was similar in the low-volume and standard-volume groups, and therefore bias from this source is unlikely. In addition, the time between completion of the preparation and the start of colonoscopy - a factor known to influence the quality of bowel preparation - was not measured and cannot be compared between the groups. The cleansing agent was self-administered by the participants and data on compliance were self-reported.

Finally, data on tolerance, satisfaction, and adverse events related to preparation were not collected. Such data might be useful to evaluate individuals' decisions not to comply with re- commended preparation, continue the preparation, or undergo screening colonoscopy; however, collecting such data would require modification of standard procedures of PCSP. Because the present study was designed and conducted as a pragmatic, randomized, health services study evaluating participation in PCPS under real life conditions, our aim was not to modify the standard procedures of PCSP. For the same reason, the information about bowel preparation was provided to screening participants in a standard way, without emphasizing potential advantages and disadvantages of low- or standard-volume regimens, and without informing the participants that they were taking part in a research study.

In conclusion, when compared with standard-volume PEG bowel preparation, low-volume sodium picosulfate/magnesium citrate bowel preparation did not improve participation or lesion detection rates, and negatively affected bowel preparation quality.

\section{Acknowledgments}

We thank Michael Bretthauer for critical review of study protocol; Ewa Kraszewska, Bartlomiej Krzeczewski, Bartlomiej Kocot, and Karolina Janikowska for their advice on study design; and Milena Laskowska, Edyta Pawlak, Elzbieta Kedzia, Magdalena Strezynska, Izabela Lapinska, Monika Flakiewicz, Aleksandra Danecka-Mormol, Pawel Brzecki, Marta Pirogowska-Lewandowska, Elzbieta Stajkowska, Piotr Woloszyn, and Robert Wloskowicz from participating screening centers for their help in conducting the study. 
This work was funded by a grant from the Foundation of Polish Science (TEAM/2012 - 9/5) financed by EU Structural Funds, Innovative Economy Operational Program 2007-2013 and supported by the Polish Ministry of Health, Medical Centre for Postgraduate Education and Polish Foundation of Gastroenterology.

\section{Competing interests}

Dr. Kaminski has taken part in advisory board meetings for Alfa Sigma and has received speaker fees from Norgine. Dr. Regula has taken part in advisory board meetings for IpsenPharma and Takeda.

\section{References}

[1] Ferlay J, Steliarova-Foucher E, Lortet-Tieulent J et al. Cancer incidence and mortality patterns in Europe: estimates for 40 countries in 2012. Eur J Cancer 2013; 49: 1374-1403

[2] Siegel RL, Miller KD, Jemal A. Cancer statistics, 2015. CA Cancer J Clin 2015; 65: 5-29

[3] Zauber AG, Sidney ], Winawer MD et al. Colonoscopic polypectomy and long-term prevention of colorectal-cancer deaths. N Engl J Med 2012; 366: 687-696

[4] von Karsa L, Patnick J, Segnan N et al. European guidelines for quality assurance in colorectal cancer screening and diagnosis: overview and introduction to the full supplement publication. Endoscopy 2013; 45 : $51-59$

[5] Richardson L, Rim S, Plescia M. Vital signs: colorectal cancer screening among adults aged 50-75 years - United States, 2008. MMWR Morb Mortal Wkly Rep 2010; 59: $808-812$

[6] Thiis-Evensen E, Kalager M, Bretthauer M et al. Long-term effectiveness of endoscopic screening on incidence and mortality of colorectal cancer: a randomized trial. United European Gastroenterol J 2013; 1: $162-168$

[7] Bretthauer M, Kaminski MF, Loberg M et al. Population-based colonoscopy screening for colorectal cancer: a randomized clinical trial. JAMA Intern Med 2016; 176: 894 - 902

[8] Segnan N, Senore C, Andreoni B et al. Comparing attendance and detection rate of colonoscopy with sigmoidoscopy and FIT for colorectal cancer screening. Gastroenterology 2007; 132: 2304-2312

[9] Lisi D, Hassan C, Crespi M. Participation in colorectal cancer screening with FOBT and colonoscopy: an Italian, multicentre, randomized population study. Dig Liver Dis 2010; 42: 371 - 376

[10] Stoop EM, de Haan MC, de Wijkerslooth TR et al. Participation and yield of colonoscopy versus non-cathartic CT colonography in population-based screening for colorectal cancer: a randomised controlled trial. Lancet Oncol 2012; 13: 55-64

[11] Inadomi JM, Vijan S, Janz NK et al. Adherence to colorectal cancer screening: a randomized clinical trial of competing strategies. Arch Intern Med 2012; 172: 575-582

[12] Quintero E, Castells A, Bujanda L et al. Colonoscopy versus fecal immunochemical testing in colorectal-cancer screening. N Engl J Med 2012; 366: $697-706$
[13] McLachlan S-A, Clements A, Austoker J. Patients' experiences and reported barriers to colonoscopy in the screening context - a systematic review of the literature. Patient Educ Couns 2012; 86: 137- 146

[14] de Wijkerslooth TR, de Haan MC, Stoop EM et al. Reasons for participation and nonparticipation in colorectal cancer screening: a randomized trial of colonoscopy and CT colonography. Am J Gastroenterol 2012; 107: $1777-1783$

[15] Jones RM, Devers KJ, Kuzel AJ et al. Patient-reported barriers to colorectal cancer screening: a mixed-methods analysis. Am J Prev Med 2010; 38: 508- 516

[16] Tan JJ, Tjandra JJ. Which is the optimal bowel preparation for colonoscopy - a meta-analysis. Colorectal Dis 2006; 8: 247-258

[17] Worthington J, Thyssen M, Chapman G et al. A randomised controlled trial of a new 2 litre polyethylene glycol solution versus sodium picosulphate + magnesium citrate solution for bowel cleansing prior to colonoscopy. Curr Med Res Opin 2008; 24: 481 - 488

[18] Park SS, Sinn DH, Kim YH et al. Efficacy and tolerability of split-dose magnesium citrate: low-volume (2 liters) polyethylene glycol vs. single- or split-dose polyethylene glycol bowel preparation for morning colonoscopy. Am J Gastroenterol 2010; 105: 1319-1326

[19] Hakama M, Malila N, Dillner J. Randomised health services studies. Int J Cancer 2012; 131: 2898-2902

[20] Kaminski MF, Kraszewska E, Rupinski M et al. Design of the Polish Colonoscopy Screening Program: a randomized health services study. Endoscopy 2015; 47: $1144-1150$

[21] Hassan C, Bretthauer M, Kaminski MF et al. Bowel preparation for colonoscopy: European Society of Gastrointestinal Endoscopy (ESGE) guideline. Endoscopy 2013; 45: 142 -150

[22] Bugajski M, Wieszczy P, Hoff G et al. Modifiable factors associated with patient-reported pain during and after screening colonoscopy. Gut 2017: doi:10.1136/gutjnl-2017-313905

[23] Regula J, Zagorowicz E, Butruk E. Implementation of a national colorectal cancer screening program. Curr Colorectal Cancer Rep 2006; 2: $25-29$

[24] Lai E], Calderwood AH, Doros G et al. The Boston bowel preparation scale: a valid and reliable instrument for colonoscopy-oriented research. Gastrointest Endosc 2009; 69: 620-625

[25] Bosman FT, Carneiro F, Hruban RH et al. WHO classification of tumours of the digestive system. Lyon: IARC; 2010

[26] Jin Z, Lu Y, Zhou Y et al. Systematic review and meta-analysis: sodium picosulfate/magnesium citrate vs. polyethylene glycol for colonoscopy preparation. Eur J Clin Pharmacol 2016; 72: 523-532

[27] Lieshout Iv, Munsterman ID, Eskes AM et al. Systematic review and meta-analysis: sodium picosulphate with magnesium citrate as bowel preparation for colonoscopy. United European Gastroenterol J 2016; 5: $917-943$

[28] Kojecky V, Matous ], Keil R et al. A head-to-head comparison of 4-L polyethylene glycol and low-volume solutions before colonoscopy: which is the best? A multicentre, randomized trial Int J Colorectal Dis 2017; 32: $1763-1766$

[29] Leitao K, Grimstad T, Bretthauer M et al. Polyethylene glycol vs sodium picosulfate/magnesium citrate for colonoscopy preparation. Endosc Int Open 2014; 2: E230 - E234

[30] Manes G, Amato A, Arena M et al. Efficacy and acceptability of sodium picosulphate/magnesium citrate vs low-volume polyethylene glycol plus ascorbic acid for colon cleansing: a randomized controlled trial. Colorectal Dis 2013; 15: $1145-1153$ 